\title{
PERSPECTIVA DO USO DAS TECNOLOGIAS DA INFORMAÇÃO E COMUNICAÇÃO NA EDUCAÇÃO DE JOVENS E ADULTOS NA CONTEMPORANEIDADE
}

\author{
Yara da Paixão Ferreira (UNEB)* \\ João Paulo Teixeira (UNEB)** \\ Antonio Amorim (UNEB)***
}

\section{RESUMO}

Este estudo teve como objetivo analisar o desenvolvimento da aprendizagem dos alunos da Educação de Jovens e Adultos (EJA) e do Programa Nacional de Integração da Educação Profissional (PROEJA) na Educação Básica na modalidade da EJA, mediante o uso das Tecnologias da Informação e Comunicação (TICs) no processo educativo. Visa identificar aspectos relevantes diante do seguinte questionamento: Diante do avanço do universo tecnológico e da comunicação, como os estudantes e professores da EJA lidam com as TICs na contemporaneidade? A metodologia utilizada foi de cunho empírico-qualitativo, dentro de uma abordagem colaborativa na área educativa. Os sujeitos da pesquisa foram discentes e docentes do CEEP Lourdes Carvalho Neves Batista, em Cícero Dantas e da EJA na Escola Anísio Teixeira, em Camaçari-BA. Foram obtidos os seguintes resultados: que as TICs são mais utilizadas na EJA profissionalizante e que os docentes necessitam de Formação continuada focando o uso das TICs.

Palavras-chave: EJA. PROEJA. TICs.

\section{ABSTRACT \\ PERSPECTIVE OF THE USE OF INFORMATION AND \\ COMMUNICATION TECHNOLOGIES IN YOUTH AND ADULT EDUCATION IN CONTEMPORANEITY}

The objective of this study was to analyze the learning development of stu-

* Professora do município de Camaçari- BA; Licenciada em Letras; Mestra em Educação de Jovens e Adultos pela UNEB- Universidade do Estado da Bahia - MPEJA. https://orcid.org/0000-0001-9593-3310E-mail: yara.dapaixoferreira@gmail.com

** Gestor do CEEP Lourdes Carvalho Neves Batista do município de Cícero Dantas - BA; Licenciado em Letras; Mestre em Educação de Jovens e Adultos pela UNEB-Universidade do Estado da Bahia- MPEJA: E-mail:joaopauloteixeira08@hotmail.com

*** Professor titular Pleno da Universidade do Estado da Bahia. Pós- Doutor em Difusão do Conhecimento pela UFBA. Doutorado em Psicologia pela Universidade de Barcelona - Espanha. https://orcid.org/00000003-3236-9159. E-mail: antonioamorim52@gmail.com 
dents of Youth and Adult Education (EJA) and the National Program for the Integration of Professional Education (PROEJA) in Basic Education in the EJA modality using Information and Communication Technologies (ICTs) in the educational process. To identify relevant aspects before the following question: before the advance of the technological universe and the communication, how the students and teachers of the EJA deal with the ICT in the contemporaneity? The methodology used was empirical-qualitative, within a collaborative approach in the educational area. The subjects of the research were students and professors of CEEP Lourdes Carvalho Neves Batista, in Cícero Dantas and of the EJA in the School Anísio Teixeira, in Camaçari-BA. The following results were obtain: those ICTs are most used in the scenario in the vocational EJA and that teachers need continuous training focusing on the use of ICTs.

Keywords: EJA; PROEJA; Information, communication and Technology.

\section{RESUMEN}

\section{PERSPECTIVA DEL USO DE LAS TECNOLOGÍAS DE LA INFORMACIÓN Y COMUNICACIÓN EN LA EDUCACIÓN DE JÓVENES Y ADULTOS EN LA CONTEMPORANEIDAD}

Este estudio pretende analizar el desarrollo del aprendizaje de adultos y Educación de la juventud (EJA) y programa de integración nacional de educación profesional (proteger) en la educación básica en la modalidad de Educación de adultos y jóvenes, mediante el uso de Tecnologías información y comunicación (TIC) en el proceso educativo. Tiene como objetivo identificar los aspectos relevantes sobre la siguiente pregunta: ante el avance tecnológico y universo de comunicación, estudiantes y maestros de adultos y jóvenes educación ocuparse de las TIC en la contemporaneidad. La metodología utilizada fue de naturaleza empírica-calidad, dentro de un enfoque de colaboración en el área educativa. Los sujetos de la investigación fueron estudiantes y maestros de CEEP Lourdes Carvalho Neves Bautista, en Cicero Dantas y de la educación de adultos y jóvenes en la escuela, Anísio Teixeira en Camaçari-BA. Se obtuvieron los siguientes resultados: que las TIC se utilizan en la educación vocacional y de adulta y que los profesores requieren educación continua centrándose en el uso de las TIC.

Palabras clave: Educación de adultos y jóvenes. PROTEGER. TIC.

\section{INTRODUÇÃO}

Na atualidade a era tecnológica e da comunicação se ressignifica e evolui de forma veloz. Nesse cenário, a tecnologia e a comunicação são componentes indispensáveis para a vida do sujeito em sociedade. Tal fenômeno surgiu no final do século XX e trouxe ao cenário mundial a "Era da Informação". Nesse contexto, a incorporação da tecnologia foi en- 
veredando na vida dos sujeitos tornando-se cada vez mais objeto de necessidade social, econômica e cultural.

A este respeito, Bonilla (2005) aponta o avanço tecnológico como uma nova organização na visão do mundo e de seus atores. Esse avanço tecnológico designou a amplitude das Tecnologias da Informação e da Comunicação - TICs em diversos seguimentos da sociedade. Diante dessa conjuntura, os espaços educacionais passaram a ser difusores desse conhecimento, principalmente se postularmos as TICs como coadjuvante no processo ensino-aprendizagem. Logo, o cenário educacional, principalmente no campo da Educação de Jovens e Adultos EJA, se faz também um cenário de (re) construção de cultura, conhecimentos e politização de saberes.

Pensando nessa sociedade tecnológica comunicacional e sua relação com a EJA, surgiu como questionamento dessa pesquisa a seguinte problemática: Diante do avanço no universo tecnológico e da comunicação, como os estudantes e professores da EJA, lidam com as TICs no processo educacional na contemporaneidade? 0 estudo em questão teve como objetivo analisar o desenvolvimento das aprendizagens e identificar aspectos relevantes no campo da EJA a partir do uso das TICs, fazendo um estudo de cunho colaborativo entre docentes e discentes do seguimento do PROEJA numa escola Estadual no Município de Cícero Dantas-BA e do seguimento da EJA em uma escola $\mathrm{Mu}$ nicipal, situada na cidade de Camaçari-BA.

O levantamento adicionado a este estudo se constituí instrumento útil no sentido de perceber a relação entre o processo e o acesso à inovação tecnológica na educação, através de seguimentos distintos da EJA: a EJA como Tempo de Formação (Eixos III e IV) e o PROEJA (Formação Técnica). Diante dessas perspectivas em relação a Educação de Jovens e Adultos, temos como campo de análise a EJA como proposta de modalidade básica de ensino e a EJA com ênfase na formação profissional, através do Programa Nacional de Integração da Educação Profissional (PROEJA).

Fato que gerou resultados diversos que abrangem desde a formação continuada docente às habilidades docentes e discentes em relação ao universo das TICs - Tecnologias e da Comunicação. Bem como perspectivas acerca das TICs no universo da educação, da aprendizagem e do ensino e a conectividade entre a EJA, as TICs e a vida dos sujeitos na sociedade. A seguir delimitamos os procedimentos do estudo através da instrumentação colaborativa que propiciou a oportunidade de participação na construção do conhecimento cientifico baseado no contexto real.

\section{PROCEDIMENTOS METODOLÓGICOS EMPREENDIDOS}

Inicialmente foi realizada uma revisão bibliográfica em busca de autores e de conceitos que assegurassem um arcabouço teórico sobre as TICs e a EJA. Tivemos como aporte teórico autores, como Nelson Pretto (1996), que trata da educação e sua relação com as multimídias, focando o contexto das TICs na educação como um campo fértil. Bonilla (2005) que fala do interfaceamento de linguagens e de tecnologias, visando a inclusão social e a permanência dos sujeitos na sociedade da informação, focando os sujeitos como produtores de culturas e conhecimentos; Amorim (2015) que aborda a inovação e a qualidade do ensino e dos saberes na educação, dentre outros autores.

No que concerne à metodologia científica aplicada utilizamos a pesquisa qualitati- 
va através da instrumentalização colaborativa pautada nas ideias de Desgagné (2007), que trata da metodologia colaborativa numa visão socioconstrutivista do "saber", relacionando a educação ao contexto de pesquisa e docência; coadunando teoria e prática de forma crítica, na produção de dados e na análise das práticas educativas.

$\mathrm{Na}$ mesma vertente, Ibiapina (2016) propõe a investigação na perspectiva colaborativa de construção de saberes implicando os agentes envolvidos em prol de uma educação igualitária e justa, através de um movimento reflexivo-colaborativo em que a docência tem potencial de análise e transformações das realidades. Logo, o processo investigativo ocorre diante da colaboração de pesquisadores e docentes no processo de pesquisa.

As etapas da pesquisa, de base instrumental colaborativa, foram iniciadas a partir da sensibilização, que é o momento de incorporação dos participantes. No segundo momento foram aplicadas estratégias da pesquisa qualitativa, utilizando: conversas informais individuais e em grupo para coleta de dados e posteriormente a aplicação de questionários semiestruturados. Após o levantamento, selecionamos as categorias e implicações relacionadas com a base teórica que fundamentou a pesquisa. Em seguida efetuamos, a análise dos dados e os resultados obtidos.

Esclarecemos que o processo da pesquisa ocorreu de forma participativa e colaborativa, onde todos foram pesquisadores. E que em conjunto, e em outro momento teremos a possibilidade de refletir, divergir e viabilizar ações, projetos, e produções a partir dos resultados obtidos através desse estudo. Possibilitando ações que possam contribuir para o ensino e aprendizagem no campo da EJA a partir das TICs. Visto que, a proposta colaborativa é uma alternativa de uma investigação a partir do vivenciado.

Teles e Ibiapina (2009) designam a pesquisa como uma alternativa de produção de conhecimentos científicos que: favorecem a formação, a pesquisa e o desenvolvimento profissional dos colaboradores; promove a reflexão crítica de significados que são compartilhados; favorece a produção de conhecimentos; supre as necessidades da pratica educativa; articula teoria e prática e promove o empoderamento dos partícipes.

Dentre os dois seguimentos educacionais relacionados a pesquisa e a EJA contamos com o seguimento do PROEJA, localizado no município de Cícero Dantas, que tem a população estimada em 32.300 habitantes com a probabilidade 33.356 de cícero-dantenses para o ano de 2018, segundo o IBGE (2010). 0 município tem a maior fonte geradora de economia na agricultura e na pecuária. 0 outro campo da pesquisa se refere a EJA como modalidade Básica de Ensino sem caráter profissionalizante, se concentra no município de Camaçari, região metropolitana do Salvador-BA, que de acordo com o último IBGE realizado de (2010) tem a população de estimada em 242.970 e a probabilidade de aumento para 293.723 pessoas no ano de 2018, Camaçari tem na indústria a atividade que gera maior rendimento monetário.

O lócus da pesquisa que teve dois seguimentos da EJA, porém com funcionalidade divergente: o CEEP - Centro Estadual de Educação Profissional Lourdes Carvalho Neves Batista, órgão Estadual, localizado na cidade de Cícero Dantas-BA. O CEEP Lourdes Carvalho Neves Batista. Escola de ensino do primeiro ao terceiro ano do ensino médio, atualmente funciona com 22 turmas, oferecendo ensino médio e técnico em administração, agropecuária e informática nos três 
turnos, atendendo a clientela de 550 alunos no total. Em relação ao turno noturno no PROEJA temos cerca de 90 alunos distribuídos entre as turmas do primeiro ao terceiro ano. O Curso do PROEJA equivalente ao Ensino Médio, constituído por 06 (seis) turmas, no turno noturno, oferece disciplinas básicas e específicas na área de Informática.

O outro seguimento da pesquisa foi a Escola Municipal Anísio Teixeira, localizada na cidade de Camaçari-BA e equivale a turmas da EJA, Eixos I a V, que funciona como Tempo de Formação (cada seguimento equivale a duas séries do ensino fundamental I). A escola "Escola Municipal Anísio Teixeira" atualmente (2017), atende o Ensino Fundamental I e II e a EJA. Mas, atende no total a 1.417 alunos distribuídos nos três turnos: matutino, vespertino e noturno. Discriminados na seguinte ordem: Ensino Fundamental dos Anos Iniciais - Fundamental I; Fundamental dos Anos Finais - Fundamental II e a EJA (Eixos: II, III, IV e V). Centralizando a EJA temos 163 alunos matriculado distribuídos em seis (turmas). No entanto, a frequência atual é 157 alunos, pois, existe o fenômeno do rodizio em relação a frequência delimitada pelo próprio aluno. Por inúmeras questões como: trabalho, falta de transporte e a violência. Em relação ao Índice de Desenvolvimento da Educação Básica (IDEB, 2017), Camaçari apresenta apenas 0,4 de diferença em relação ao município de Cicero Dantas que apresenta o índice de 4,4 em detrimento de 4,8 de Camaçari (QEdu, 2017).

Para o processo de pesquisa delimitamos seguimentos A e B para designamos as Escolas, o CEEP Lourdes Carvalho - PROEJA como escola A e a Escola Anísio Teixeira como escola B. Os sujeitos da pesquisa foram oito discentes e oito docentes de ambas as escolas, totalizando 32 colaboradores. Os alunos da escola A, quanto da escola B, dentre eles 16 sujeitos do sexo feminino e 16 sujeitos do sexo masculino dentre estes: desempregados, ambulantes, trabalhadores formais, informais e com idades entre 17 à 60 anos no seguimento $A$, e no seguimento $B$ discentes de 15 à 80 anos de idade.

0 corpo docente do CEEP Lourdes Carvalho foi representado por 16 professores da Área Técnica (disciplinas específicas) e Base Comum (disciplinas básicas) do Curso Técnico em Informática, onde todos fizeram um processo seletivo REDA, por formação acadêmica relacionada as suas áreas de conhecimento. Os mesmos possuem idade que variam de 25 a 45 anos; e, em especial os professores das disciplinas básicas, em sua maioria, por não dominarem o uso das tecnologias, contam com o auxílio de monitores / estagiários (estudantes do curso de Informática), autorizados pela Secretaria do Estado.

Enquanto que na Escola B (Escola Anísio Teixeira) contamos com 16 professores com idade variável entre 38 à 60 anos distribuídos em disciplinas da Educação Básica, que possuem formação acadêmica e que na sua grande maioria foram admitidos via concurso público, tendo apenas um (01) docente sem formação em educação, cuja formação se foca no setor da Contabilidade.

\section{AS TICS E O CONTEXTO DA APRENDIZAGEM NA EJA}

0 uso das tecnologias no contexto educacional apareceu há mais de 60 anos, mas seu uso tem sido questionado em vários aspectos. Um deles é sobre a inserção das TICs de forma adequada e como mais uma estratégia na aquisição do conhecimento de forma consciente e intencional por parte dos professores e alunos.

Em relação a utilização eficaz das TICs, Gonsales (2013, p. 57) destaca que [...] após 
a Revolução Industrial, antes do advento da Internet, a informação era prioritariamente física, impressa: livros, discos, CDs, apostilas, enciclopédias, dentre outros instrumentos. Portanto, a não materialidade da informação se torna de difícil adaptação para muitos educandos da EJA. Sendo necessária a percepção do conhecimento multifacetado, compartilhado, dinamizado como necessidade de sobrevivência na sociedade.

No Brasil, a partir de 2005 o uso das TICs na educação ganhou maior impulso, através do Decreto de no 5.622/2005, que regulamenta o Artigo 80 da Lei no 9.394, de dezembro de 1996, que estabelece a Lei de Diretrizes e Bases da Educação Nacional - LDB. Esse decreto oficializou a Educação a Distância (EAD) como modalidade educacional, ampliando o universo de acesso a educação, oportunizando a mediação didático-pedagógica nos processos de ensino e aprendizagem através da utilização de meios e tecnologias da informação e da comunicação. Com essa possibilidade de desenvolvimento educativo através da tecnologia, estudantes e professores também passaram a ter maior possibilidade de desenvolver atividades educativas em lugares e tempos diversos. No entanto, ressaltamos que em alguns espaços educacionais, o acesso a essas tecnologias não está disponível ou vem sendo disponibilizado de forma escassa. Logo, percebemos discrepâncias em relação ao uso da TICs e os objetivos pedagógicos em algumas situações.

Uma dessas discrepâncias se faz perceptível na modalidade da EJA, que de acordo a LDB traz as TICs como ponto principal para inserção no mundo do trabalho. Ao atentarmos para a inclusão da Lei de $\mathrm{n}^{\mathrm{o}}$ 11.741/2008, Art.o 3, que destaca que a EJA deverá articular-se preferencialmente com a educação profissional, na forma do regula- mento. No entanto se faz contraditório, sabendo-se que a EJA tem um perfil de diversidade e pluralidade de sujeitos e objetivos. Portanto, não cabe articular o uso das TICs potencializando apenas a educação profissional.

Dessa forma, fica evidenciado que o uso das TICs não é visto no campo da EJA como uma aprendizagem para a vida do sujeito em sociedade. As TICs geralmente são vistas, prioritariamente como ferramenta para possível inserção no mundo do trabalho. Sendo assim, e os educandos não são percebidos como sujeitos de possibilidades, conhecimentos e vivências diversas. Muito menos, vistos como sujeitos que possuem direito ao acesso e a aprendizagens diversas, inclusive as tecnológicas.

Na atualidade, o cotidiano e a vida em sociedade está integrado ao universo das TICs e dentro do contexto das desigualdades sociais em alguns casos o contato com a tecnologia é acessível em espaços públicos. Pois, estamos num processo constante de transformações tecnológicas e digitais e que consequentemente produzem impactos sociais, políticos, econômicos e culturais.

Logo, as escolas e os espaços educacionais populares podem ocasionar uma forma positiva para que os sujeitos da EJA se socializem e se relacionem com o mundo. Assim, as escolas devem utilizar de tal ferramenta no processo emancipador dos sujeitos da EJA. Proporcionando a facilidade ao acesso; ao armazenamento de informações; a interatividade, com a pretensão de potencializar as capacidades cognitivas. E como fator motivacional, facilitador, metacognitivo propiciando o compartilhamento do conhecimento no ambiente de aprendizagem.

0 professor também pode utilizar a tecnologia de forma atrativa e motivadora na EJA, embora muitos ainda não estejam pre- 
parados para aproveitá-la como um instrumento de aprendizagem para os alunos da EJA. Tal estratégia poderá ser incentivadora para o uso das TICs pelos discentes da EJA. Visto que, muitos de nossos alunos não percebem que o uso das TICs são ferramentas necessárias para sua vida cotidiana. Dessa forma, as práxis pedagógicas na EJA podem ser ferramentas no combate às desigualdades socioeconômicas e culturais.

Hoje é consenso que as novas tecnologias de informação e comunicação podem potencializar a mudança do processo de ensino e de aprendizagem e que, os resultados promissores em termos de avanços educacionais relacionam-se diretamente com a ideia do uso da tecnologia a serviço da emancipação humana, do desenvolvimento da criatividade, da autocrítica, da autonomia e da liberdade responsável. (ALMEIDA; PRADO, 1999, p.1).

$\mathrm{Na}$ contemporaneidade, a tecnologia e a aprendizagem caminham juntas. Por isso, as demandas educativas podem e devem ser usadas para a construção de novas aprendizagens através de um ambiente colaborativo virtual, que agilize a comunicação, a interação e o compartilhamento do conhecimento através de tecnologias disponíveis. Neste contexto são realizadas pesquisas sobre as TICs na Educação no Brasil desde 2010 com o propósito de investigar usos pedagógicos, habilidades de professores e alunos, as dificuldades do uso das TICs e os avanços Barbosa esclarece sobre alguns estudos e pesquisas em relação as TICs na educação indicando que:

No Brasil, a produção de indicadores sobre o uso das TICs na Educação é parte da missão do Centro Regional de Estudos para o Desenvolvimento da Sociedade da Informação, do Núcleo de Informação e Coordenação (NIC.br), que tem ligação com o Comitê Gestor da Internet no Brasil (CGI.br), que desde 2010 tem realizado pesquisas sobre as TIC na Educação com o objetivo de mensurar os usos e apropriações das TICs nas escolas brasileiras, nas suas práticas pedagógicas e na gestão escolar (BARBOSA, 2013, p.28).

Assim, as TICs já têm demonstrado seu desenvolvimento e eficiência no campo da educação, mas também não se pode negar que a construção do conhecimento tem sido feita para além das paredes de sala de aula, isto fica perceptível na vida cotidiana de qualquer sujeito na realização de atividades corriqueiras do seu dia, como no uso de caixas eletrônicos, no cartão de passagem do ônibus e até mesmo no uso de aparelhos de som e TV.

Pois estamos interagindo com as TICs a todo e a qualquer momento de nossas vidas. Sendo assim, a inserção das TICs no processo da aprendizagem promove de alguma forma o processo de criticidade do sujeito, pois a medida que ele vai interagindo e conhecendo a evolução tecnológica ele constrói saberes individuais e coletivos.

Concepções que afirmam que as TIC possibilitam novas formas de ordenação da experiência humana, com múltiplos reflexos na área cognitiva e nas ações práticas, ao possibilitar novas formas de comunicação e produção de conhecimento, gerando com isso transformações na consciência individual, na percepção de mundo, nos valores e nas formas de atuação social. (BONILLA, 2005. p. 246).

Com base na argumentação acima, percebemos que incluir o sujeito das classes da EJA, na sociedade da informação não se delimita apenas na alfabetização digital, pois é uma questão muito mais abrangente, e se espera que o cidadão seja capaz de participar, questionar, produzir, decidir, transformar, sendo parte integrante da dinâmica social, em todas as suas instâncias. Não significando apenas o acesso as TICs mas, a construção do pensamento crítico, ou seja, o 
educando deve perceber que também existe uma postura capitalista na inserção das TICs e na vida social dos sujeito.

Sendo assim, nossos educandos podem entender que a todo momento são produzidos amontoados de aparelhos tecnológicos, que são colocados como instrumento de poder econômico. E que também fazem parte dessa discussão as questões planetárias e ambientais que percorrem este universo, como por exemplo a imensa produção de lixo tecnológico produzido diariamente.

É necessário salientar que a aprendizagem através das TICs, não apresenta apenas a aprendizagem e evolução individual e sim uma aprendizagem que possibilita o cuidado com o coletivo. Nesse sentido, o uso das TICs promove cidadãos reflexivos, críticos e com ideais de preservação e de responsabilidade social.

[...] no contato com as tecnologias que os sujeitos vão tomando conhecimento dos diferentes sistemas simbólicos, tematizando e compreendendo seu contexto, e isso não se efetiva num curto espaço de tempo, nem se restringe à alfabetização digital [...]aponta, rapidamente, a necessidade de, além da alfabetização digital, capacitar as pessoas para a utilização das mídias em favor dos interesses e necessidades individuais e comunitárias, com responsabilidade e senso de cidadania. (BONILLA, 2005, p. 71-73).

Dessa forma, a escola sobretudo a EJA, deve propiciar aos seus educandos a possibilidade de inovação e a qualidade de saberes diversos. Sendo assim, é eficaz que se perceba o uso das TICs de forma dinamizada, democrática e efetiva. Nesse âmbito, todos devem estar imbuídos no mesmo processo, inclusive a Gestão, que deve ser pautada numa gestão que possibilite a ampliação e propagação de conhecimentos a todos os envolvidos no processo de aprendizagem.
Nesse contexto de tornar a escola numa instituição viva, com um ambiente transformador e propício à construção e consolidação de melhorias sistematizadas, há que se compreender essa instituição em sua totalidade envolvida por todas as suas especificidades, um lugar dinâmico onde existe a vida democrática dos alunos, dos professores, dos gestores, dos servidores e dos pais dos alunos, com todos atuando de maneira coletiva e efetiva (AMORIM, 2015, p. 409).

Nesse sentido, cabe também ao gestor inserir propostas e projetos que propiciem conhecimentos diversos, inclusive das TICs. Assim, ele estará propiciando uma educação contemporânea, democrática e eficaz; onde todos trabalham em forma de rede: professores, alunos, gestão e comunidade. Nesse processo que envolve a educação na EJA e as TICs, destacamos a necessidade do trabalho em rede, pois envolver toda a comunidade interna e externa da escola se faz necessário.

Isto também delimita uma ação pedagógica na EJA. Uma educação pautada nos sujeitos e suas especificidades, seus anseios, suas histórias e seus conhecimentos de vida. Nesse sentido, o trabalho colaborativo e em rede faz da escola um organismo vivo e transformador de sujeitos e de sua comunidade.

\section{AS TICS E A FORMAÇÃO CONTINUADA NA EJA}

A formação continuada é de vital importância em qualquer seguimento profissional, principalmente no contexto docente da EJA, que traz alguns resquícios de uma educação tradicional que nos é cobrada pelo próprio aluno. Por outro lado, observamos que alguns docentes não foram preparados para esse novo conhecimento digital e comunicativo que evolui de forma constante, Guerra traz a discussão das TICs não só como prática educativa e do mundo do trabalho. Mas, 
também como possibilidade de criticidade e reflexão do sujeito:

Através da experiência docente vivida nas últimas três décadas, percebemos que dentro de uma visão conservadora, onde o conhecido, o tradicional, nos deixa numa favorável zona de conforto temos a educação persistindo como uma prática educativa centrada no professor, nas técnicas, nos métodos e na execução por parte do aluno das atividades a ele impostas. 0 modelo educacional tradicional ainda é baseado na transmissão de conhecimento, no qual o aluno é considerado sujeito passivo, sem capacidade crítica e reflexiva, com uma 4 visão de mundo segundo a que lhe foi transmitida. Porém se pensamos na sociedade e no mundo do trabalho, formar um profissional nesse contexto é negligenciar a possibilidade dele sobreviver em uma sociedade do conhecimento que solicita um sujeito com habilidades e competências para a inovação, criatividade e senso crítico. (GUERRA 2012, p.3-4).

No campo educacional, as novas TICs são de suma importância para o processo ensino aprendizagem, principalmente no campo da EJA que possuí diversidades e especificidades entre seus sujeitos. No entanto, se faz necessário que os docentes acompanhem a evolução tecnológica da informação e da comunicação. Pois, para muitos docentes a evolução tecnológica se faz uma nova experiência, principalmente em relação a velocidade que ela acontece. Nesse âmbito, a Formação continuada docente deve pleitear o uso das TICs como ferramenta didático -pedagógica.

Até por que, pedagogicamente o uso das TICs podem ampliar o universo de conhecimento tanto para o discente, quanto para o docente. Visto que, as tecnologias estão inseridas no campo da educação com legitimidade desde a década de 80 , através da LDB no 9394/96. Sendo assim, o uso das TICs em sala de aula justifica-se por três principais razões: adaptar-se aos diversos estilos de aprendizagem, aumentar a motivação dos alunos e reforçar o material a ser ensinado (PRAIS; REIS; DUTRA, 2015, p.2).

Gadotti (2013) designa que a educação deve primar principalmente pela qualidade social da educação, onde se acentua o aspecto social, cultural e ambiental da educação, em que se valoriza não somente o conhecimento simbólico, mas também, o conhecimento sensível e o técnico. Neste contexto, o docente contemporâneo deve estar inserido nas evoluções e conhecimentos atuais. Sendo assim, a formação continuada passa a ser necessária à medida que estamos numa sociedade em desenvolvimento e de constantes mudanças.

Para que as TICs se torne realmente algo significativo na construção da aprendizagem do aluno, é necessário que o educador tenha conhecimentos sobre as tecnologias não tendo apenas a disposição de softwares educativos, mas também consiga envolver o aluno através do seu real objetivo, principalmente em escolas da EJA. Assim, vincula-se o mundo das TICs como instrumento usado para a emancipação do sujeito, inserção no mundo tecnológico, do lazer e também como veículo de acesso ao mundo do trabalho.

Portanto, a tecnologia no campo da EJA deve se expandir a nível de conhecimento técnico e profissional, mas sobretudo de vida em sociedade. Até por que, muitos educandos da EJA ainda se sentem excluídos do mundo tecnológico, situando o uso das TICs como um instrumento de utilização cognitiva e não como um instrumento de necessidade no seu cotidiano de vida, de acessibilidade e de inclusão social. Logo, as TICs na aprendizagem da EJA propõem um conhecimento que poderá ampliar o universo pedagógico do docente, que consequentemente poderá propor inovações e novas ferramen- 
tas, ampliando seu universo profissional e efetivo com uma EJA baseada na realidade dos sujeitos.

A utilização das TICs e softwares educacionais não podem e nem devem ser utilizados de modo aleatório, ou como um passatempo para a aula. Os softwares devem ser escolhidos de acordo com as necessidades apresentadas pela turma, sendo que o mesmo deve oportunizar uma interação entre professor/aluno e conteúdo proposto. Assim, a utilização dos recursos tecnológicos pode ser vista como sendo uma metodologia diferenciada, que pode aproximar o aluno do ambiente de aprendizagem.

A Informática tornou-se uma necessidade no mundo em que vivemos, e a escola, na missão de preparar o indivíduo para a vida, sente a responsabilidade de não fechar os olhos para esta realidade [...] não se pode negar que a informática faz parte de nossas vidas, mesmo que pertençamos a um país em desenvolvimento. (WEISS, A; CRUZ, M., 2001, p.14).

Diante do que foi exposto, entendemos que a inserção da tecnologia nas unidades escolares, principalmente, no campo da EJA, precisa está fundamentada em alguns fatores fundamentais, dentre os quais é possível destacar a formação docente, ambientes apropriados e máquinas em bom estado, pois, o professor não deve apenas conhecer instrumentos tecnológicos e sim saber utilizá-los da melhor forma possível.

No que concerne a formação de futuros professores e as TICs, as universidades também necessitam ser veículo de propagação do uso das TICs na Educação e na vida dos sujeitos, principalmente no campo da EJA, já excluído de muitos direitos: à cultura, à educação e à vida. Assim, no que concerne a Políticas Públicas em relação as TICs e o campo da EJA, notamos que a Formação continuada dos docentes é de primordial importância.
De acordo com Silveira (2001, p. 18) “[...] hoje, presenciamos a existência de uma nova agenda pública inserida nesta revolução tecnológica com o objetivo de enfrentar a exclusão digital". E o primeiro passo para isso, com certeza, é socializar o uso das TICs nas escolas. Até por que, a cada dia estamos mais submersos em um ambiente tecnológico, e, de certa maneira, o que se observa é uma reestruturação nas suas formas de pensar, sentir e de agir no mundo.

Pretto (1996, p. 141) enfatiza que “[...] não estão sendo formados os profissionais para o mundo que se está construindo ao tempo que as mudanças ocorrem de forma muito veloz e em grandes dimensões". Neste contexto, percebemos a necessidade da formação continuada para docentes, pois, muitos dos educadores, sentem a necessidade de aperfeiçoamento em relação as infraestruturas tecnológicas e/ou comunicacionais, o que determina atenção por parte dos governos na definição de suas políticas educacionais. Pois, apesar de alguns cursos oferecidos aos professores, a distância pelo MEC (Ministério da Educação) em todo país, não são suficientes para suprir a necessidade de aperfeiçoamento profissional dos docentes em relação às TICs.

Portanto, percebemos que para se obter êxito nesse processo, é necessário que cada profissional envolvido perceba que as mudanças resultantes da adoção de tais novidades tecnológicas têm a pretensão de proporcionar a construção de novas formas de ensinar e aprender, pois estamos na era da comunicação, contudo, ainda existe dificuldade dos docentes na interação com estes novos símbolos tecnológicos e comunicativos do mundo atual. Fato que designa a necessidade de maiores investimentos em políticas educacionais voltadas a educação e a tecnologia, visando produção de culturas e 
conhecimentos, desde a formação docente, propagando também a formação continuada, partindo do pressuposto que o universo das TICs são dinâmicos e constantes.

Ao refletir sobre a utilização das TICs no processo ensino-aprendizagem na EJA temos que pensar numa aprendizagem interativa e de redes de saberes e transformações "Nesse contexto as TIC potencializam as diferentes formas de conhecimento, condicionando o fazer e o saber dos sujeitos em processo permanente de interação com a realidade" (CASTRO; SANTOS; SOUZA, 2017, p.168-169).

As TICs trazem desafios e novos cenários para a educação, o século XXI perpassa pela inovação tecnológica no ensino-aprendizagem. Ferramentas diversas, já promovem a comunicação interativa na aprendizagem como chats, vídeo conferências e outros instrumentos e canais tecnológicos e comunicativos. Assim, já não é opcional a Formação continuada dos docentes em relação as TICs, já se faz uma necessidade fundante no fazer educacional.

\section{RESULTADOS DA \\ INVESTIGAÇÃO COLABORATIVA}

A pesquisa de instrumentalização colaborativa se delimitou através da cooperação de docentes e discentes, de espaços e contextos diferentes, porém com a pretensão de colaborar mutuamente. Esse processo investigativo demonstrou a importância das Ticos, pois alguns questionários que coletamos foram emitidos via e-mail. Assim, a colaboração e aprendizagem se utilizou do uso das TICs como veículo de troca e informação de saberes. A colaboração também foi eminente na análise dos resultados, visto que os pesquisadores e sujeitos da pesquisa apontaram aspectos relevantes sobre a aprendizagem na EJA e a sua relação com as TICs.
Inicialmente percebemos a diversidade em relação a faixa etária dos alunos. Na Escola CEEP Lourdes Carvalho Neves Batista, o PROEJA (Programa Nacional de Integração da Educação Profissional) possuí alunos de 17 a 60 anos. Em contrapartida as classes da Escola B, consistem na faixa etária dos 16 aos 80 anos. Esses dados, permitem analisar que a EJA enquanto modalidade escolar agrega alunos de uma faixa etária maior, o que nos faz refletir que os objetivos do PROEJA prioriza a formação profissional e o preparo para o mercado do trabalho.

Nesse contexto, $80 \%$ da escola CEEP Lourdes Carvalho Neves Batista-PROEJA informaram usar as TICs no seu cotidiano. E apenas $20 \%$ declararam não utilizar constantemente. Já na Escola B 40\%, declararam não utilizarem as TICs no cotidiano, enquanto $60 \%$ disseram utilizar as TICs na sua vida diária. 0 que demonstra que grande parte dos discentes do PROEJA utilizam a tecnologia no seu cotidiano.

A falta de infraestrutura, equipamentos e laboratório de informática foi citado como um dos fatores condicionantes em relação a eficácia na aprendizagem com o uso das TICs na Escola B, 90\% dos educandos, relataram não usarem as TICs na escola. E 10\% declaram utilizar com seus próprios recursos. Porém, os alunos da Escola A destacaram $100 \%$ da utilização das TICs, porém enfatizando o maior uso no Laboratório de informática.

Esta diferenciação em relação aos usos das TICs em Laboratório na escola, estabeleceu-se, principalmente, devido a divergência entre a estrutura física, profissional e material entre os dois espaços de aprendizagem, visto que, a escola A possuí um laboratório de informática onde acontece as aulas práticas de Informática com 40 computadores em funcionamento. E que também, 
dispõe de uma sala que realiza atividades de montagem e conserto de máquinas e instrumentos tecnológicos. Enquanto, a Escola B, mantém um laboratório como deposito de sucatas.

Ressaltamos também, que na Escola $\mathrm{A}$ existem projetos, e trabalhados na unidade em relação a tecnologia e que incidem em criações e descobertas tecnológicas, e são difundidos em outros locais como exemplo NTE (Núcleo Territorial do Estado). Estes projetos representados pelos alunos do PROEJA são custeados pelo Governo do Estado da Bahia.

Em contrapartida a escola B, Escola Municipal Anísio Teixeira, além de ser gerenciada e mantida pelo município, não tem como proposta fundante o mundo do trabalho. E não consegue trazer a tecnologia e a comunicação através de possibilidades que podem ser implementadas pelo mundo virtual. Visto que, possui um laboratório de informática, desativado a 8 anos por diversas questões como: equipamentos obsoletos e quebrados; falta de monitor para o acompanhamento dos professores no uso das tecnologias; corte de internet; falta de formação continuada dos docentes, dentre outros problemas. Ou seja, na escola B não existe uma infraestrutura que possibilite o acesso dos educandos ao universo das TICs de forma direcionada e com os instrumentos necessários, inclusive para um trabalho coletivo envolvendo os educandos e docentes.

Ao tratarmos do uso das TICs extra laboratório, mas em sala de aula com disciplinas diversas, os alunos da escola $A$, relataram que apenas $60 \%$ dos docentes utilizarem tabletes, celulares e net books em suas aulas. Em detrimento de 40\% que não utilizam destes recursos. E 90\% declararam maior contato com o mundo das TICs no laborató- rio ao realizar criação de vídeos, configuração de redes de computadores, construção de páginas de web, dentre outras atividades ligadas às TICs. Apenas 10\% dos alunos da Escola A não declararam tais realizações, abstendo-se da resposta.

Em relação aos docentes da Escola A, cerca de $40 \%$ sinalizaram não utilizarem aparelhos tecnológicos por acreditar que a disciplina voltada as TICs, já faz esse papel, pois o profissional e o laboratório de informática promovem essa aprendizagem. Sendo assim, se concentram no ensino dos conteúdos da disciplina. Já na escola B, 80\% os alunos informaram que os docentes não utilizam as TICs em sala de aula, alegando que na escola não existe equipamentos e nem um laboratório de informática com um monitor disponível. Porém, sinalizaram que $20 \%$ utilizam celular e note book. Em relação ao contato com o mundo das TICs, $50 \%$ declaram maior contato através do celular ou caixa eletrônico. Em detrimento de $50 \%$ que dizem não estabelecerem contato, usando apenas celular para atender e fazer chamada telefônica.

Em relação ao uso das TICs pelos os docentes da Escola B 20\% declaram utilizarem por seus recursos próprios net book ou celular que utilizam esporadicamente para pesquisar em grupo. Em detrimento de 80\% que disseram não utilizar por conta de não terem equipamentos suficientes na escola, inclusive até os mais obsoletos como aparelho de som por exemplo.

Vale ressaltar que a aprendizagem através das TICs não condiz apenas a aprendizagem do mundo do trabalho, e de conteúdos escolares. Mas, condiz com uma necessidade de dar autonomia ao sujeito, pois em algumas classes da EJA podemos encontrar rejeição a aprendizagem das TICs por diversos fatores, inclusive cultural e geracional. 
Percebemos tal fato em uma fala de um discente da Escola B, que diz "[...] não confio em pagamento de conta por computador e celular...meus pagamentos e na boca do caixa". Tal afirmativa reflete a necessidade da democratização do uso das TICs em todos os espaços inclusive na EJA. Estamos no século XXI e as TICs fazem parte do cotidiano dos sujeitos e se faz necessário que este conhecimento seja difundido como direito para todos.

Andre Lemos (2004, p.24) coaduna com essa ideia quando destaca que "Participar, ser cidadão na era digital é mais do que estar conectado e consumir a distância; é atuar no ciberespaço com a perspectiva comunitária e política, sendo cibersujeito ". Ou seja temos que formar a cidadania na cibercultura ${ }^{1}$, na sociedade da informação, pois estamos cada vez mais imersos na era digital. Portanto, as TICs não estão vinculadas apenas ao ensino EAD, as salas de bate-papo e cursos on-line. Elas evoluíram e se modernizaram e inovaram a vida em sociedade.

No entanto, alguns docentes ainda rejeitam um maior contato com as TICs, ou mesmo estabelecem que essa ferramenta não fora utilizada a anos atrás e que a educação se estabelecia com eficácia. Outros já, destacam a necessidade de Formação continuada docente voltada ao uso das TICs, o que poderá propiciar uma educação includente na EJA. Logo, as TICs não podem ser vistas como uma disciplina fora do contexto pedagógico.

Em meio ao cotidiano do sujeito e do espaço educacional temos que fazer das TICs

1 A cibercultura é a relação entre as tecnologias de comunicação, informação e a cultura, emergentes a partir da convergência informatização/telecomunicação na década de 1970. Trata-se de uma nova relação entre tecnologias e a sociabilidade, configurando a cultura contemporânea (Lemos, 2002). uma ferramenta a favor do sujeito da EJA, não como um conhecimento distante de sua realidade. Assim, um simples celular, uma imagem de um e-mail e outras construções pedagógicas poderão ser utilizadas como processo tecnológico de aprendizagem. Sendo assim, o docente poderá inserir as TICs no universo da EJA como ferramenta de comunicação inerente a vida diária de todos os sujeitos na sociedade.

E que por mais, que pareça estranho, ou desnecessário para alguns. Haverá um momento em que será uma necessidade crucial na vida e no cotidiano de todos. Desde as tarefas mais difíceis, até as mais comuns. 0 que sugere, que estejamos abertos e disponíveis às aprendizagens do mundo tecnológico e da comunicação. Neste âmbito os docentes da EJA podem ser o universo de inserção das TICs na prática pedagógica da EJA. Daí, entendermos a importância dessa aprendizagem. Visto que acompanhar a tecnologia e seus avanços já não é uma escolha para o sujeito e sim uma necessidade de sobrevivência em meio a sociedade.

Percebemos que o uso das TICs tem maior predominância na Escola $\mathrm{A}$, por ter o laboratório e os equipamentos funcionando, condições físicas e profissionais. Porém, a de se ressaltar que tanto os docentes quanto os discentes de ambas escolas, acreditam que as TICs são mais presentes através do professor de informática. Ou seja, os professores acreditam que uso das TICs é parte exclusiva do Laboratório de Informática e do professor exclusivo da área de informática.

Outro aspecto relevante se refere as condições tecnológicas de cada espaço apresentando distorção entre as duas escolas. Enquanto a Escola A, possuí um aparato físico e tecnológico a seu favor. A escola $B$, dispõe de poucos recursos tecnológicos e os que existem estão sucateados. Fato que demonstra 
que, o Estado apresenta melhores condições para o uso das TICs nos programas do PROEJA. Enquanto, a nível municipal as condições tecnológicas apresentam precariedade, até mesmo em estabelecer a proposta da LDB de 1996, que prioriza o preparo profissional.

Quadro 1 - 0 quadro abaixo destaca os aspectos relevantes positivos e negativos relacionados ao uso das TICs na aprendizagem nos contextos da EJA

\begin{tabular}{|c|c|c|}
\hline $\begin{array}{l}\text { ASPECTOS } \\
\text { POSITIVOS }\end{array}$ & $\begin{array}{c}\text { ASPECTOS } \\
\text { NEGATIVOS }\end{array}$ & $\begin{array}{c}\text { ASPECTOS CONJUNTO } \\
\text { ENTRE AS DUAS } \\
\text { ESCOLAS }\end{array}$ \\
\hline $\begin{array}{l}\text { ESCOLA A } \\
\text { Dinamiza e motiva a práxis } \\
\text { pedagógica; } \\
\text { Laboratório de Informática; } \\
\text { Monitores e Estagiários na } \\
\text { área das TIC; } \\
\text { Espaço físico; } \\
\text { Disponibilidade de } \\
\text { instrumento e aparelhos } \\
\text { tecnológicos; } \\
\text { Criação de protótipos } \\
\text { tecnológicos; } \\
\text { Sala de consertos e reparos. }\end{array}$ & $\begin{array}{l}\text { Falta de cursos de } \\
\text { aperfeiçoamento das TICs } \\
\text { para os professores da } \\
\text { Base Comum. }\end{array}$ & $\begin{array}{l}\text { Positivos: As TICs podem } \\
\text { corroborar no processo } \\
\text { ensino aprendizagem; } \\
\text { Reconhecimento de } \\
\text { formação continuada em } \\
\text { relação às TICs. }\end{array}$ \\
\hline $\begin{array}{l}\text { ESCOLA B } \\
\text { As TICs podem corroborar no } \\
\text { processo da aprendizagem. }\end{array}$ & $\begin{array}{l}\text { Distorção: faixa etária } \\
\text { Falta de profissional de } \\
\text { Informática (monitor); } \\
\text { Equipamentos sucateados; } \\
\text { Professores com } \\
\text { pouco conhecimento } \\
\text { tecnológico; } \\
\text { Falta de espaço físico e } \\
\text { tecnológico; } \\
\text { Resquícios de uma } \\
\text { educação tradicionalista. }\end{array}$ & $\begin{array}{l}\text { Negativos: As TICs como } \\
\text { proposta Laboratorial } \\
\text { no processo ensino- } \\
\text { aprendizagem; } \\
\text { Os professores da Base } \\
\text { Comum na sua grande } \\
\text { maioria não possuem } \\
\text { formação continuada no } \\
\text { campo das TICs. }\end{array}$ \\
\hline
\end{tabular}

Fonte: Elaborado pelos autores, 2016.

Ao analisarmos os dados percebemos que as TICs são importantes no processo educativo em ambos seguimentos da EJA. No entanto, ainda existe a ideia de que as Tecnologias e a comunicação estão direcio- nadas ao profissional da Informática que muitas vezes não é um professor graduado, é um monitor, que não tem formação pedagógica e educacional. Nesse contexto, a EJA deve pleitear a inserção das TICs como 
aliada ao processo ensino-aprendizagem Castro; Santos e Souza falam dessa relação quando dizem que:

[...] a inserção das TIC no contexto de aprendizagem da EJA, como uma possibilidade de ressignificação da prática pedagógica e a constituição do sujeito autor. Nesse contexto, as TIC potencializam as diferentes formas de conhecimento, condicionando o fazer e o saber dos sujeitos em processo permanente de interação com a realidade. (CASTRO; SANTOS; SOUZA, 2017, p.168-169).

Portanto, apesar dos professores reconhecerem a necessidade de Formação continuada na área das TICs no campo da EJA ainda acreditam que as TICs têm caráter instrumental, ou seja necessita de um laboratório de Informática com a presença de um monitor para acompanhar os alunos. Na Escola A percebemos a priorização da LDB de 1996, no que se refere a profissionalização para o trabalho e na Escola B, as TICs são vistas pelos docentes como uma aprendizagem para a vida cotidiana e relatam que não adianta receber cursos de formação se as condições da aplicabilidade são precárias, declara o professor da Escola B: “[...] pra que tomar curso de tecnologia se não temos os equipamentos funcionando e disponíveis". Declara o aluno da Escola B ..." não temos nem acesso a uma simples xerox, pois a máquina tá pra consertar tem três anos e nada".

Veiculando os aspectos positivos em relação as ao uso das TICs na aprendizagem a pesquisa demonstrou a relevância de 90\% entre as duas escolas em detrimento de apenas $10 \%$. Em relação a esse dado Padilha traz a percepção das TICs como proposta didática e atraente no processo ensino-aprendizagem:

Do ponto de vista do docente e da escola, um dos temas mais relevantes é o sem número de oportunidades de criação de novas didáticas. As tecnologias representam uma porta para um diálogo instigante entre docentes e estudantes. Diálogo que, sabidamente, deve ser reinventado a fim de se evitar não apenas o crescente desinteresse dos estudantes pelas situações de aprendizagem tradicionalmente oferecidas pelas escolas, como também para tornar mais atraente, prazeroso e compensador o ofício do educador. 0 desafio, no entanto, não é insuperável e seu caminho passa, necessariamente, pela formação docente. (Padilha, 2013, p. 81).

A formação continuada relacionada ao uso das TICs, no processo de ensino-aprendizagem da EJA possui grande relevância, diante da necessidade dos docentes e discentes em aprimorar o uso das tecnologias e da comunicação de forma eficaz. Tais declarações deixam em evidência que, de acordo com Amorim (2007) necessitamos de uma escola inovadora na contemporaneidade, mas algumas escolas continuam no imobilismo, seguindo uma educação tradicional e conteudista. Tal posicionamento, também nos conduz a pensar que a educação tem utilizado as TICs apenas como uma novidade, não atentando que as mesmas são potencializadoras da prática educativa e social.

Assim, alguns educadores não percebem que inserir as TICs no mundo da EJA é emancipar o sujeito, efetivando uma aprendizagem significativa. Incluindo o sujeito no mundo social, cultural e econômico. Pois, lamentavelmente, alguns docentes ainda acreditam que a tecnologia é um inimigo em potencial da aprendizagem. Pois, ainda temos educadores que pensam em uma educação estática e arcaica.

Padilha (2013) situa a necessidade de formação dos docentes em relação as TICs, sendo necessário a apropriação desse conhecimento que compõe o social, o cultural, o econômico e todas as vivências e espaços 
do mundo contemporâneo. Sendo, a EJA enquanto modalidade suprimida desse conhecimento sendo direcionado a exclusão tecnológica.

Ao pensarmos na formação inicial ou continuada do docente quebramos paradigmas em relação a educação tradicional, excludente e bancária Santos ressalta essa ideia quando diz que:

Para que ocorra uma mudança de concepção, faz-se necessário que os cursos de formação (inicial e continuada) de professores também ofereçam a esses profissionais orientações didático-metodológicas sobre as melhores formas de selecionar e utilizar recursos tecnológicos no processo educativo escolar. Os docentes precisam, pois, saber da existência das potencialidades/possibilidades (vantagens) e limitações (desvantagens) desses e de outros recursos didático -pedagógicos para melhor ensinar, e assim ajudar os alunos a (re) construir novos conhecimentos úteis a sua aprendizagem e a sua vida pessoal e profissional. (SANTOS, 2011, p. 77).

A esse respeito, Bonilla (2005, p. 244) afirma que as TICs possibilitam novas formas de ordenação da experiência humana, gerando com isso transformações na consciência individual, na percepção de mundo, nos valores e nas formas de atuação social. Através da pesquisa realizada foram encontrados dados relevantes, que apresentam semelhanças e diferenças entre o PROEJA e a EJA, em relação as TICs na práxis pedagógica e no fazer educacional, demonstrando que a EJA, apresenta divergências e distorções em relação ao uso e a aprendizagem.

Porém, a relação entre as TICs e a educação é intrínseca e já faz parte das vivências e das relações humanas seja no cognitivo ou nas atividades diárias. 0 que pressupõe Políticas Públicas e pesquisas que implementem maiores possibilidades de inserção e aprimoramento das TICs no contexto da EJA primando não só pelo mundo do trabalho, mas para a vida cotidiana e coletiva dos sujeitos.

\section{CONSIDERAÇÕES FINAIS}

Fica explícito que as escolas que oferecem a EJA, como modalidade não possuem suporte tecnológico, o que diverge do seguimento do PROEJA. Ressaltando que mesmo diante do aparato tecnológico disponível no PROEJA muitos docentes ainda, não se sentem preparados para utilizar a tecnologia apesar de alguns professores terem a disponibilidade de aparelhos e instrumentos tecnológicos. E que apresentam uma pedagogia profissionalizante, seguindo a proposta da LDB relacionada ao preparo profissional. 0 que evidencia o viés tecnicista e de produção capitalista. Portanto, não apresenta o verdadeiro propósito da educação libertadora e emancipatória.

É evidente que as TICs ampliam as possibilidades profissionais, no entanto a EJA apresenta especificidades que devem ser respeitadas. Na EJA enquanto modalidade, a pesquisa demonstra que os municípios não investem em equipamentos tecnológicos no sentido de profissionalização dos discentes. E que existe a carência destes equipamentos para utilização dos docentes, o que impossibilita o uso de tecnologia como ferramenta pedagógica e no desenvolvimento cognitivo.

Outro fato relevante é a necessidade de Formação continuada para os docentes em relação as TICs, que acreditam que as TICs são direcionadas apenas ao âmbito do Laboratório da Informática. Fica explicito que as escolas que oferecem a modalidade da EJA, ainda apresentam o viés tecnicista e de educação tradicional. Portanto, não apresenta o verdadeiro propósito da educação na EJA 
que propõe a Educação emancipatória. Alguns docentes resistem a mudança, a inovação no campo da EJA através da TICs não percebendo que as TICs já não se situam apenas no uso da tecnologia para comunicação, mas para a o cotidiano do indivíduo.

A relação entre as TICs e a educação no campo da EJA, pressupõe a inclusão sociodigital a favor do desenvolvimento da sociedade e do sujeito. Percebemos que dentro da modalidade da EJA ainda existem discrepâncias e certo teor do mundo da produção. Pois, a educação ainda apresenta o ranço capitalista em relação ao discurso fortalecido nas escolas, sobretudo de cunho profissionalizante, que apresentam uma educação que prioriza o mundo do trabalho.

No entanto, ressaltamos que apesar dos docentes acreditarem no potencial das TICs no processo aprendizagem, eles se mostram pouco familiarizados no uso das ferramentas tecnológicas. Eles acreditam que as tecnologias são apenas instrumentos que são explorados nas aulas de Informática e nos laboratórios, sendo aplicadas pelos professores desses seguimentos.

Destacamos também, que os aparelhos e instrumentos tecnológicos são presentes e de uso efetivo na modalidade profissionalizante, em contrapartida, temos verdadeiras sucatas tecnológicas ocupando o espaço físico na modalidade da EJA, que corresponde ao tempo de formação, visto que, os aparelhos e instrumentos estão amontoados nos cantos das escolas, servindo apenas como lixo tecnológico e ocupação do espaço físico.

Referente a utilização da TICs pelos docentes no processo ensino aprendizagem, fica explicito que enquanto, as escolas profissionalizantes tratam as TICs com a função de inserção no mercado de trabalho, a modalidade da EJA Tempo de Formação na sua grande maioria, percebe essa utilização apenas no ato de pesquisa de sites e como trabalho a ser desenvolvido extraclasse.

No que concerne a Formação continuada os docentes envolvidos declaram que a sua realização, é necessária pela velocidade contida no mundo das TICs e na sua relação com a sociedade. Isto fica explicito, quando alguns docentes revelam sua deficiência perante o uso das TICs. A pesquisa evidenciou a necessidade de multiplicação, implementação e viabilização de novas políticas educacionais, programas e projetos voltados as TICs na área da educação para formação inicial e continuada de professores. Abrindo campo de possibilidades visto que, ainda são oferecidas formações para os docentes de forma limitada e ineficaz. Pois, não adianta oferecer cursos com programas e mídias avançadas, quando não se tem ao menos o conhecimento básico tecnológico.

Outra questão em destaque é o fator "poder" que alguns gestores da EJA apresentam em relação as TICs, em relação ao detrimento das ferramentas e equipamento tecnológicos que devem ser utilizados apenas pelos discentes e docentes não estabelecendo uma aprendizagem em rede envolvendo a comunidade.

Fica claro que discentes e docentes na sua grande maioria acreditam na possibilidade da TICs serem necessárias na aprendizagem. No entanto, percebemos que no que concerne ao campo da EJA, na sua totalidade não enfatizam as especificidades e diversidades do sujeito. Logo, o processo aprendizagem não está vinculado à proposta inicial da EJA que é emancipar e politizar sujeitos em prol de uma sociedade menos desumana e capitalizada. Portanto, o uso das TICs na EJA deve estar baseado nas especificidades da EJA. Valorizando as identidades e diversidades: culturais, sociais e econômicas de sujeitos e de comunidades. 
Portanto, as TICs podem ser utilizadas em qualquer seguimento da EJA, pois, devem ser vistas como aliadas na construção do conhecimento. 0 que pleiteia a construção de um currículo educacional inovador, que vise a ação educativa transformadora e emancipatória. Já que as TICS estão no cotidiano da vida dos sujeitos. E a educação é um veículo de propagação social, cultural, econômica e tecnológica. Essa postura requer uma educação igualitária e não recortada no viés tradicionalista, produtivista e segregador que impera na sociedade brasileira.

Nesse contexto as TICs podem ser utilizadas em qualquer seguimento da EJA. No entanto, devem ser vistas como aliadas na construção do conhecimento, mas também como colaboradora de uma educação para a vida, visando uma ação educativa transformadora e emancipatória, já que as TICS estão no cotidiano da vida dos sujeitos e a educação tecnológica e da comunicação é um veículo de propagação social, cultural, econômica e tecnológica.

\section{REFERÊNCIAS}

ALMEIDA, M. E. B. \& PRADO, Maria E. B. B. Um retrato da informática em educação no Brasil. 1999. In: http://www.proinfo.gov.br. Acesso em: $02 \backslash 11 \backslash 2016$.

AMORIM, A.Inovação, qualidade do ensino e saberes educacionais: caminhos da gestão escolar contemporânea. Ver. Ibero-Americana de Estudos em Educação. v.10, n.2, 2015.Disponivél em:<http://www.seer.fclar.unesp.br>.Acesso em: 23 de nov. 2016.

; DANTAS. R.T; DANTAS. R. T; AQUINO. S. M. Educação de Jovens e Adultos: políticas públicas, formação de professores, gestão e diversidade multicultural. In: Part. I: EJA: Políticas Públicas e Gestão. Proinfo, inclusão digital e EJA: integração necessária na rede municipal de ensino. Salvador, EDUFBA, 2017.p.163-179.

BARBOSA A. F. (coord). Pesquisa sobre o uso das tecnologias de informação e comuni- cação nas escolas brasileiras: TIC Educação 2013. 2014. Disponível em http://www.cetic. br/media/docs/publicacoes/2/TIC_DOM_ EMP_2013_livro_eletronico.pdf. Consultado em 14/11/2014.

BARBOSA A. F. (coord). Pesquisa sobre o uso das tecnologias de informação e comunicação nas escolas brasileiras: TIC Educação 2013. 2014. Disponível em http://www.cetic. $\mathrm{br} / \mathrm{media} /$ docs/publicacoes/2/TIC_DOM_ EMP_2013_livro_eletronico.pdf. Consultado em $14 / 11 / 2014$.

GONZALES. P. Recursos educacionais abertos, formação de professores e o desafio de educar na cultura digital. Parte I São Paulo.2013. p.56-60. Disponível em <https://www. cetic.br/media/docs/publicacoes/2/tic-educacao-2013.pdf> Acesso em: 10 de abr.2017.

PADILHA. M. Das tecnologias digitais à educação: nova cultura e novas lógicas para a formação docente. Parte I São Paulo.2013. p.8186. Disponível em <https://www.cetic.br/media/docs/publicacoes/2/tic-educacao-2013. pdf> Acesso em: 10 de abr.2017.

BONILLA, Maria Helena Silveira. Escola aprendente: para além da Sociedade da Informação. Rio de Janeiro: Quartet Editora, 2005.

BRASIL. Decreto 5.622, de 19 de dezembro de 2005. Regulamenta o artigo 80 da Lei no 9.394, de dezembro de 1996, que estabelece as diretrizes e bases da educação nacional. Diário Oficial [da] República Federativa do Brasil. Brasília, DF, 20 dez. 2005. Disponível em: <http://www.planalto.gov.br/ccivil_03/_Ato20042006/2005/ Decreto/D5622.htm>. Acesso em: 25 jan. 2010.

BRASIL. Secretaria de Educação Fundamental. Parâmetros curriculares nacionais: terceiro e quarto ciclos do ensino fundamental - introdução aos parâmetros curriculares nacionais. Brasília: MEC/SEF, 1998.

COLL, C.; MONERO, C. (Org.). Psicologia da Educação virtual: aprender e ensinar com as Tecnologias da Informação e da Comunicação. Cap.I 0 impacto das TIC sobre a educação e a psicologia da educação.p.15-46. Disponível em: <https://www.larpsi.com.br/media/mconnect_uploadfiles/c/a/cap_01klp.pdf.

DESGAGNÉ, Serge. O conceito de pesquisa co- 
laborativa: a ideia de uma aproximação entre pesquisadores universitários e professores práticos. Revista em Questão. Natal, v.29, n.15, p.7-35, mai/ago. 2007.

FREIRE, P. Pedagogia do Oprimido. Rio de Janeiro. Paz e Terra. 62.ed. 2016.

GADOTTI, M. Qualidade na educação: uma nova abordagem. Florianópolis. COEB. 2013.

GUERRA, R. V. Educação de Jovens e Adultos: a ação docente diante das novas formas de informação e comunicação. IX ANPED Sul. Seminário de Educação da Região Sul. 2012. Disponível<http://www.ucs.br/etc/conferencias / index.php/anpedsul/9anpedsul/paper/viewFile/301/236>Acesso em 08 jan2017.

IBIAPINA, M. L. M. Ivana; BANDEIRA, M. M. Hilda; ARAUJO, M. A. Francisco. Pesquisa Colaborativa: multirreferenciais e práticas convergentes. Piauí: Edufpi, 2016. p.301-320.

Pesquisa colaborativa: investigação, formação e produção de conhecimentos. Brasília: Líber Livro Editora, 2008. 136p.

LEMOS, A. Cibecultura. Tecnologia e Vida Social na Cultura Contemporânea. Sulina, Porto Alegre., 2002
LEMOS, André. Cibercidades: um modelo de inteligência coletiva. In: LEMOS, A. (org). Cibercidade: as cidades na cibercultura. Rio de Janeiro: E-papers, 2004.

SANTOS, Marcos Pereira dos. Recursos didático-pedagógicos na educação matemática escolar: uma abordagem teórico-prática. Rio de Janeiro: Ed. Ciência Moderna Ltda, 2011.

SILVEIRA, S. A. da. Exclusão digital: a miséria na era da informação. São Paulo, 2001.

PRAIS.S.D.L.J; REIS. D. V.I. J; DUTRA.A. 0 uso das TICs no atual contexto educacional: formação docente frente às novas tecnologias. Revista Tecnológica na Educação. Ano 7- número 13. Dezembro 20154. http://tecnologiasnaeducacao.pro.br/ XII Seminário Nacional de Formação dos profissionais da Educação .

PRETTO, Nelson De Luca. Uma escola sem/ com futuro: educação e multimídia, Campinas: Papirus, 1996.

WEISS, A. M. L.; CRUZ, M. R. L. M. da. A Informática e os problemas escolares de aprendizagem. 3. ed. Rio de Janeiro; DP\&A, 2001.

Recebido em: 19/02/2019 Aprovado em: 06/05/2019 